\title{
Effect of Temperature on the Capacitance of a Silicon Solar Cell in Static Regime
}

\author{
Gökhan Sahin \\ Electric and Electronic Engineering Department, IĞDIR University, Iğdır, Turkey \\ Email: gokhan.sahin@igdir.edu.tr
}

How to cite this paper: Sahin, G. (2018) Effect of Temperature on the Capacitance of a Silicon Solar Cell in Static Regime. Energy and Power Engineering, 10, 187-197. https://doi.org/10.4236/epe.2018.105013

Received: February 27, 2018

Accepted: May 21, 2018

Published: May 24, 2018

Copyright $\odot 2018$ by author and Scientific Research Publishing Inc. This work is licensed under the Creative Commons Attribution International License (CC BY 4.0).

http://creativecommons.org/licenses/by/4.0/

\begin{abstract}
This work was based mainly on the capacitance of a silicon solar cell monofaciale in static conditions under monochromatic illumination and under the influence of temperature. Solving the continuity equation for excess minority carrier's charge density in the base of the solar cell resulting in the term of the temperature equation in the presence of an optical source. The latter has allowed us to obtain the photocurrent density and photovoltage. Subsequently we studied the capacitance situation of open circuit and short circuit depending on the temperature. Finally with the determination of capacitance under $\mathrm{C}_{0}$ darkness.
\end{abstract}

\section{Keywords}

Capacitance, Photocurrent, Photo Voltage, Temperature

\section{Introduction}

Temperature is a very important parameter and cannot be neglected in the behavior of solar cells. Knowing that the total incident energy (100\%), a small portion $(13 \%)$ is reflected by the surface of the sensor and this small portion is extracted as electrical energy, therefore a large portion of energy is dissipated as heat [1]. This lead, under radiation at a relatively high operating temperature if not converted into electrical energy, is not drained. In this article, we will study the effect of temperature on the capacitance ability of a silicon solar cell monofaciale under monochromatic illumination under static conditions.

The study will be based primarily on the capacitance (open circuit in Short circuit, under dark), after studying the effect of temperature on the density of minority carriers, the photocurrent density, and photo voltage. 


\section{Theoretical Background}

This solar cell is $n+-p-p+$ (Figure 1 ) whose base is p-type. So the excess minority carrier's charge in the base is electrons. This translates into the greater mobility of electrons compared to that of [2] [3] [4] holes:

In the remainder of this study, the contribution of the issuer as well as the crystalline field that exists within the base has been neglected [5]. The solar cell is discussed in one dimension with the original axis taken at the junction. When the solar cell is illuminated, various phenomena occur there, governed by the following continuity equation [6]:

$$
\begin{gathered}
\frac{\partial^{2} \delta(x)}{\partial x^{2}}-\frac{\delta(x)}{L^{2}}=-\frac{g(x)}{D} \\
g(x)=\phi(\lambda) \alpha(\lambda)(1-R(\lambda)) \mathrm{e}^{(-\alpha(\lambda) x)} \\
(L(T))^{2}=\tau D(T) \\
D(T)=\mu \frac{k_{b}}{q} T
\end{gathered}
$$

$\delta(x)$ is denotes the density of electrons generated in the base at position $x,(\lambda)$ is the flow monochromatic incident light; $\alpha(\lambda)$ is the absorption coefficient of monochromatic to the wavelength of material $\lambda ; R(\lambda)$ is the monochromatic reflectance of the material to the wavelength $\lambda ; k_{b}$ is Boltzmann's constant; $q$ is the elementary charge of an electron; $\tau$ is the lifetime of electrons in the base; $D$ the diffusion coefficient of the electrons generated in the base [7]. It is a function of $T ; L$ is the diffusion length of the electrons generated in the database, it is linked to the flow of particles. It is a function of $T ; \mu$ is the coefficient of electron mobility, $g(x)$ is the generation rate of carriers.

Equation (1) is a differential of the second degree with second member whose general solution is:

$$
\delta(x)=A \cosh \left(\frac{x}{L}\right)+B \sinh \left(\frac{x}{L}\right)-\frac{\phi(\lambda) \alpha(\lambda) L^{2}(1-R(\lambda)) \mathrm{e}^{(-\alpha(\lambda) x)}}{D\left(L^{2}(\alpha(\lambda))^{2}-1\right)}
$$

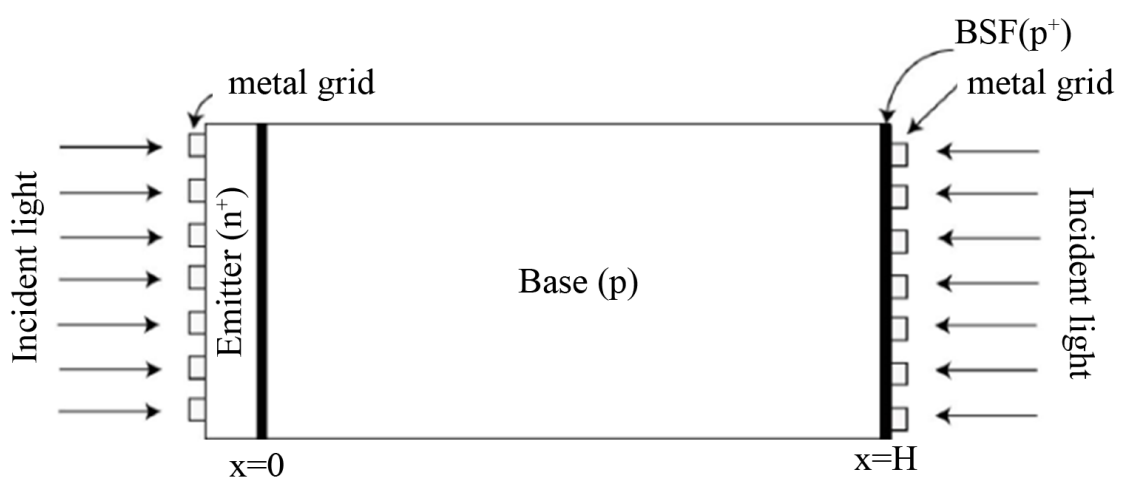

Figure 1. Bifacial silicon solar cell. 
$A$ and $B$ are constants which are determined by the two following boundary conditions:

At the junction $(x=0)[8][9]$

$$
\left.\frac{\partial \delta(\omega, x, T)}{\partial x}\right|_{x=0}=\frac{S f}{D} \cdot \delta(\omega, 0, T)
$$

At the rear side $(x=H)$

$$
\left.\frac{\partial \delta(x)}{\partial x}\right|_{x=H}=-\left.\frac{S_{b}}{D} \delta(x)\right|_{x=H}
$$

$S_{f}[8]$ and $S_{b}[10]$ are respectively the junction recombination velocity at the junction and at the rear. Let us now study the excess minority carrier's density, whose profile is obtained from Equation (4).

\section{Results and Discussion}

\subsection{Excess Minority Carrier’s Density}

Figure 1 and Figure 2 are showed the excess minority carrier's charge density in open circuit and short-circuit condition depth in the database for different values of the temperature.

At Figure 1, we see that when the depth $x$ increases, the carrier density decreases. And also for a low value of the depth (at about $x<0.005 \mathrm{~cm}$ ) when the temperature increases, the carrier density decreases. By cons for $x$ greater than about $0.005 \mathrm{~cm}$, the carrier density is increased when the temperature is low. At Figure 2, we see that near $0 \mathrm{~cm}$ carrier density increases with depth and becomes maximum to values of $x$ near close to $0 \mathrm{~cm}$. From this maximum value,

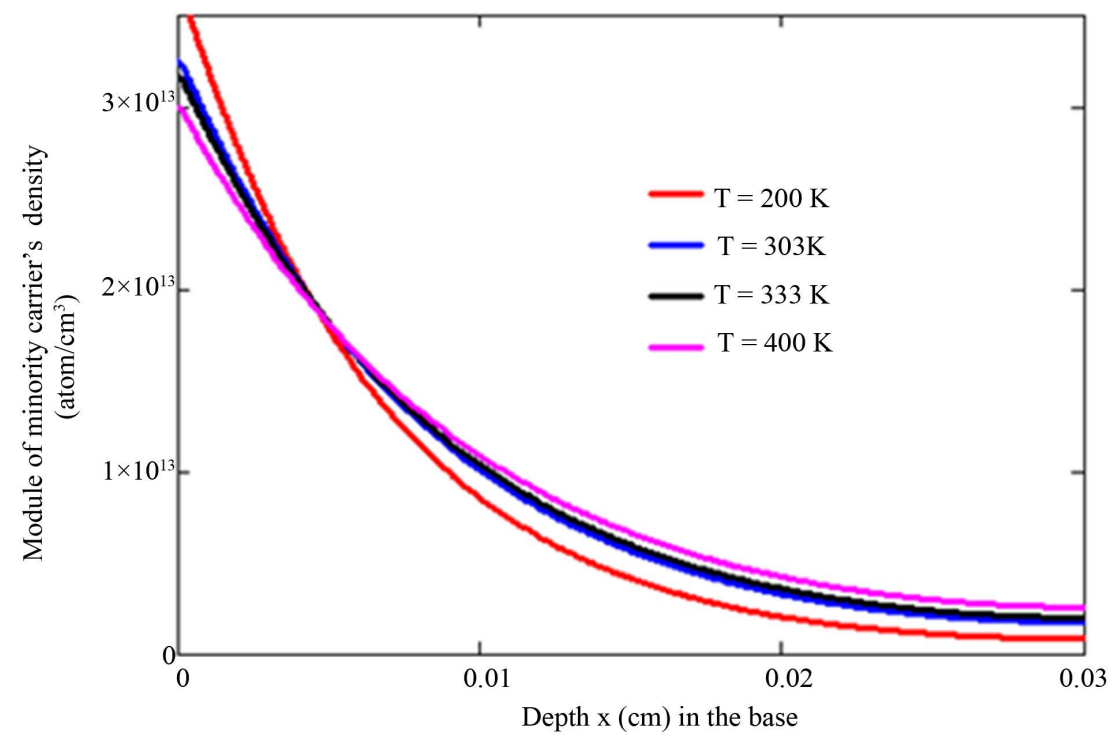

Figure 2. density profile of excess minority carrier's charges of the solar cell short circuit depending on the depth in the base for different temperature values $\left(S_{b}=2 \times 10^{2} \mathrm{~cm} / \mathrm{s}\right.$, $S_{f}=6 \times 10^{6} \mathrm{~cm} / \mathrm{s}, \lambda=0.48 \mu \mathrm{m}$. 
the carrier density regresses when the depth $x$ progresses. And also for a low value of the depth (at about the $x$ is lower than $0.015 \mathrm{~cm}$ ) when the temperature increases, the carrier's density decreases.

However, for $x$ greater than about $0.015 \mathrm{~cm}$, the temperature of excess minority carrier's density is increased. The decrease of excess minority carrier's density versus depth for the two figures is explained by the fact that there recombination volume of excess minority carrier. Regarding temperature has an excitatory function, which explains the behavior of the carrier density.

\subsection{Photocurrent Density}

The photocurrent resulting from the diffusion of the density of minority carriers at the junction and its expression is given by [6]-[11].

$$
J_{p h}\left(S_{b}, S_{f}, \lambda, T\right)=\left.q D \frac{\partial \delta\left(x, S_{b}, S_{f}, \lambda, T\right)}{\partial x}\right|_{x=0}
$$

Figure 3 below shows the photocurrent density as a function of the recombination velocity for different values of the temperature.

We observe that for small values of the recombination velocity at the junction $S_{f}\left(S_{f}\right.$ less than $\left.2 \times 10^{2} \mathrm{~cm} / \mathrm{s}\right)$ corresponding to open circuit, the photocurrent density is almost zero because the carriers are stored at the junction. From this value up to almost $5 \times 10^{5} \mathrm{~cm} / \mathrm{s}$, the photocurrent density increases with that of Sf because some carriers starts passing through the junction. High values $S_{f}\left(S_{f}\right.$

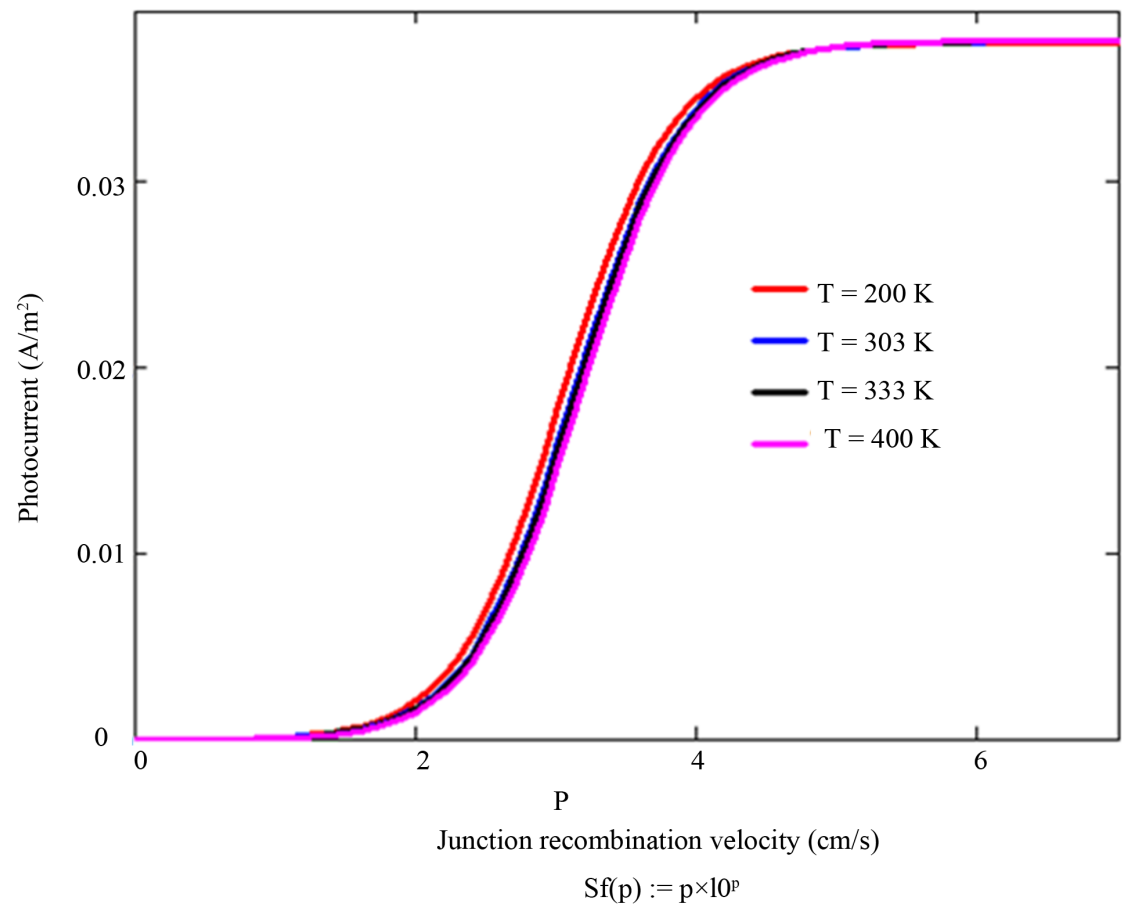

Figure 3. Photocurrent density as a function of the junction recombination velocity for different temperature values $\left(S_{b}=2 \times 10^{2} \mathrm{~cm} / \mathrm{s}, S_{f}=6 \times 10^{6} \mathrm{~cm} / \mathrm{s}, \lambda=0.48 \mu \mathrm{m}\right)$. 
greater than $5 \times 10^{5} \mathrm{~cm} / \mathrm{s}$ ) corresponds to the short-circuit because the maximum of carriers across the junction. As between $2 \times 10^{2}$ and $5 \times 10^{5} \mathrm{~cm} / \mathrm{s}$ when the temperature increases, the photocurrent density decreases. Therefore $5 \times 10^{5}$ $\mathrm{cm} / \mathrm{s}$ is the short-circuit increasing the temperature causes one of the photocurrent density. Having made the study of the photocurrent density, are now considering the photo voltage.

\subsection{Photo Voltage}

The voltage harvested under monochromatic illumination across the solar cell and use the Boltzmann relation, the photo voltage can be expressed by [10]:

$$
V_{p h}\left(S_{b}, S_{f}, \lambda, T\right)=V_{T} \ln \left(\frac{N_{b}}{n_{i}^{2}} \delta\left(0, S_{b}, S_{f}, \lambda, T\right)+1\right)
$$

where $V_{T}$ is the thermal voltage, $N_{b}$ doping rate, or the concentration of minority carriers charge.

$$
\begin{gathered}
V_{T}=\frac{k_{b}}{q} T \\
n_{i}^{2}=A \cdot T^{3} \exp \left(-\frac{E_{g}}{k_{b} \cdot T}\right)
\end{gathered}
$$

$A$ is a specific constant of the material; $n_{i}$ is the density of intrinsic carrier temperature.

Figure 4 shows the photo voltage depending on the junction recombination velocity (Sf) for different temperature value.

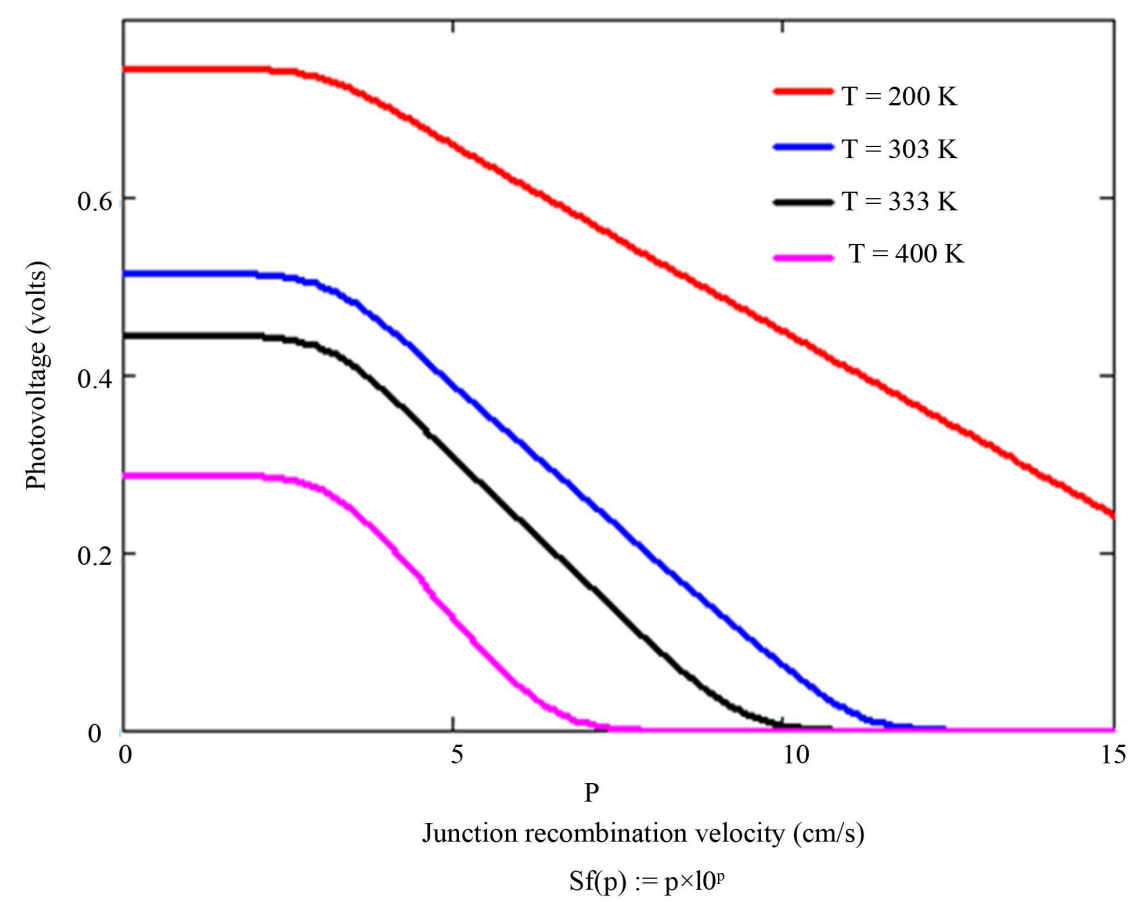

Figure 4. Photo voltage profile as a function of the recombination rate for different temperature values $\left(S_{b}=2 \times 10^{2} \mathrm{~cm} / \mathrm{s}, \lambda=0,48 \mu \mathrm{m}\right)$. 
We note that for low values of the junction recombination velocity corresponds to the open circuit where the carriers are stored at the junction recombination velocity; the photo voltage is at its maximum. Then she starts to decline from certain values of junction recombination velocity, now some carriers are beginning to cross the junction. Photo voltage tends to invalidity for high junction recombination velocity values corresponding to short circuit when the maximum carriers pass the junction. Also when the temperature is increasing, the photo voltage is decreasing.

\subsection{Dark Capacitance}

The diffusion capacitance of the solar cell is known as the resulting ability of the load change during the diffusion process within the solar cell [12]-[19]. It is expressed by the following term:

$$
C\left(S_{b}, S_{f}, \lambda, T\right)=\frac{\mathrm{d} Q\left(S_{b}, S_{f}, \lambda, T\right)}{\mathrm{d} V\left(S_{b}, S_{f}, \lambda, T\right)}
$$

As

$$
Q=q \delta(x=0)
$$

was as follows:

$$
C=q \frac{\mathrm{d} \delta(x=0)}{\mathrm{d} V}
$$

Equation can be mentioned as follows:

$$
C=q \frac{\mathrm{d} \delta(x=0)}{\mathrm{d} S_{f}} \frac{1}{\frac{\mathrm{d} V}{\mathrm{~d} S_{f}}}
$$

Taking into account the expression of the photo voltage and the excess minority carrier's density, we obtain the following expression:

$$
C=\frac{q\left(n_{0}(T)\right)^{2}}{N_{b} V_{T}}+\frac{q \delta\left(x=0, S_{b}, S_{f}, \lambda, T\right)}{V_{T}}
$$

So

$$
c=c_{1}+c_{2}
$$

where

$$
c_{1}=\frac{q\left(n_{0}(T)\right)^{2}}{N_{b} V_{T}}
$$

is the intrinsic capacitance (ability to darkness) and depends on the nature of the material through the intrinsic concentration is the ability of the solar cell due to the illumination. The following two figures show the ability of the solar cell in open circuit condition and short circuit as a function of junction recombination velocity for different values of the temperature. $n_{0}$, through doping $N_{b}$ and $V_{T}$ thermal potential. 


$$
c_{2}=\frac{q \delta\left(x=0, S_{b}, S_{f}, \lambda, T\right)}{V_{T}}
$$

where $C_{0}$ is the solar cell capacitance under dark. Equation 19 can be rewritten in the form

$$
C\left(S_{b}, S_{f}, \lambda, T\right)=C_{0} \exp \left(\frac{V_{p h}}{V_{x}}\right)
$$

With the logarithm function, we rewrite equation 20 as:

$$
\ln C-\ln C_{0}=\frac{V_{p h}}{V_{T}}
$$

Equation (21) can be expressed as follows:

$$
\ln C\left(S_{b}, S_{f}, \lambda, T\right)=\frac{1}{V_{T}} \cdot V_{p h}\left(S_{b}, S_{f}, \lambda, T\right)+\ln C_{0}
$$

At Figure 5 we observe that for small values of the junction recombination velocity $S_{f}$ concordant to open circuit, which holders are stored; capacity is at its peak. At this level the capacity remains virtually constant. Also this time the increasing temperature causes a drop in capacity. We note in Figure 6 that the capacity regresses when the junction recombination velocity rises. This can be explained by the fact that the capacitance is the measure of the ability of the capacitor to store the charges on its plates; in other words, it is a measure of its power storage. Whereas when the junction recombination velocity is low (Figure 5) holders are almost immobile, the maximum capacity and decreases with temperature excites carriers where increased thermal agitation. Where junction

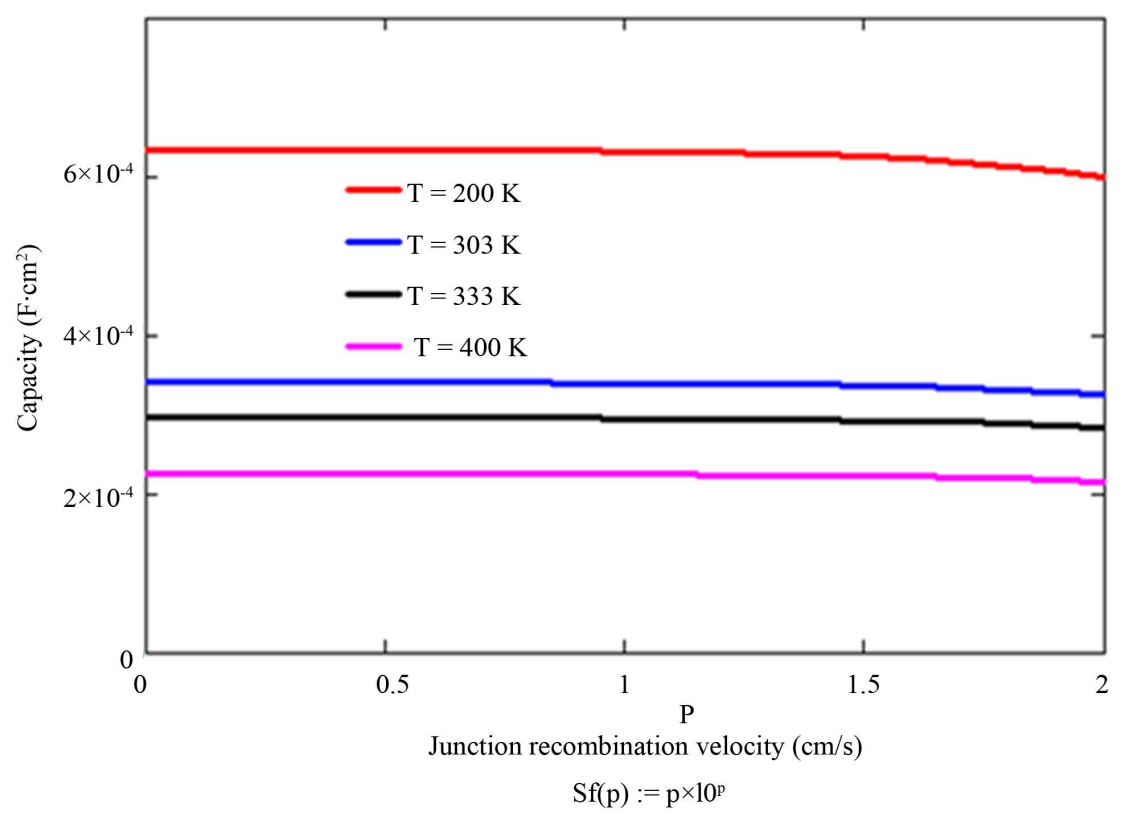

Figure 5. Capacitance of the solar cell open circuit according to the junction recombination velocity for different temperature values $\left(S_{b}=2 \times 10^{2} \mathrm{~cm} / \mathrm{s}, \lambda=0.48 \mu \mathrm{m}\right)$. 


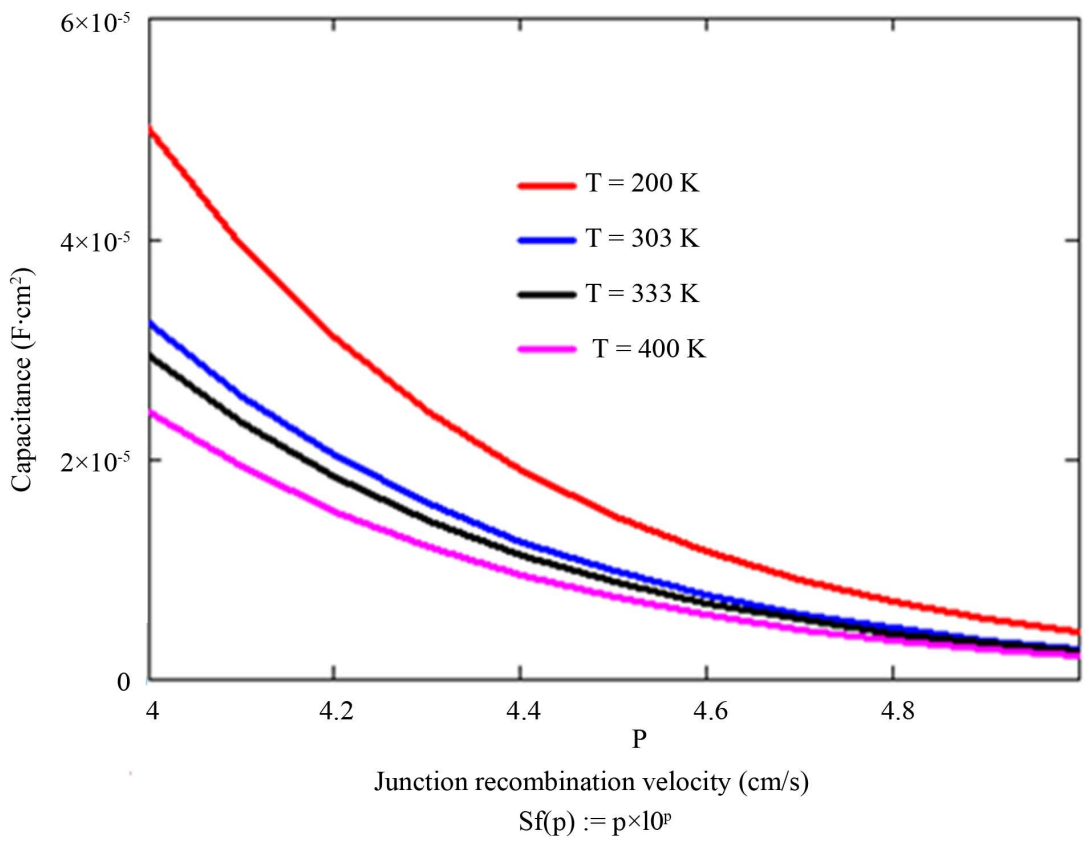

Figure 6. Capacitance of the solar cell shorted according to the junction recombination velocity for different temperature values.

recombination velocity is high (Figure 6) the holders are movable in reduced capacitance.

The following figure describes the ability of the solar cell in open-circuit condition in function of temperature for different wavelength values.

We find open circuit at the level of Figure 7 that the capacity decreases with increasing temperature. And also decreases for shorter wavelengths. The following figure shows the capacity of the solar cell in a situation of short-circuit in function of temperature for different values of the wavelength.

At Figure 8 where we have the ability to short-circuit situation; we note that the moment the temperature is increased, the capacity is decreasing. The following figure shows the natural logarithm of the capacitance $C$ with different values of the natural logarithm of the capacity under darkness $C_{0}$ according to the photo voltage for different values of the temperature. The logarithm of the capacitance curves versus photo voltage for various temperature values are given in Figure 9.

From this figure we have determined for each temperature value in its corresponding capacitance $C_{0}$ darkness. The temperature value is a straight line of slop $1 / V_{T}$.

$C_{0}$ these values are given by Table 1 .

The study of this table shows that when the temperature rises, the darkness under $C_{0}$ capacity also increases.

\section{Conclusions}

A theoretical study of a solar cell with monofaciale under static regime under 


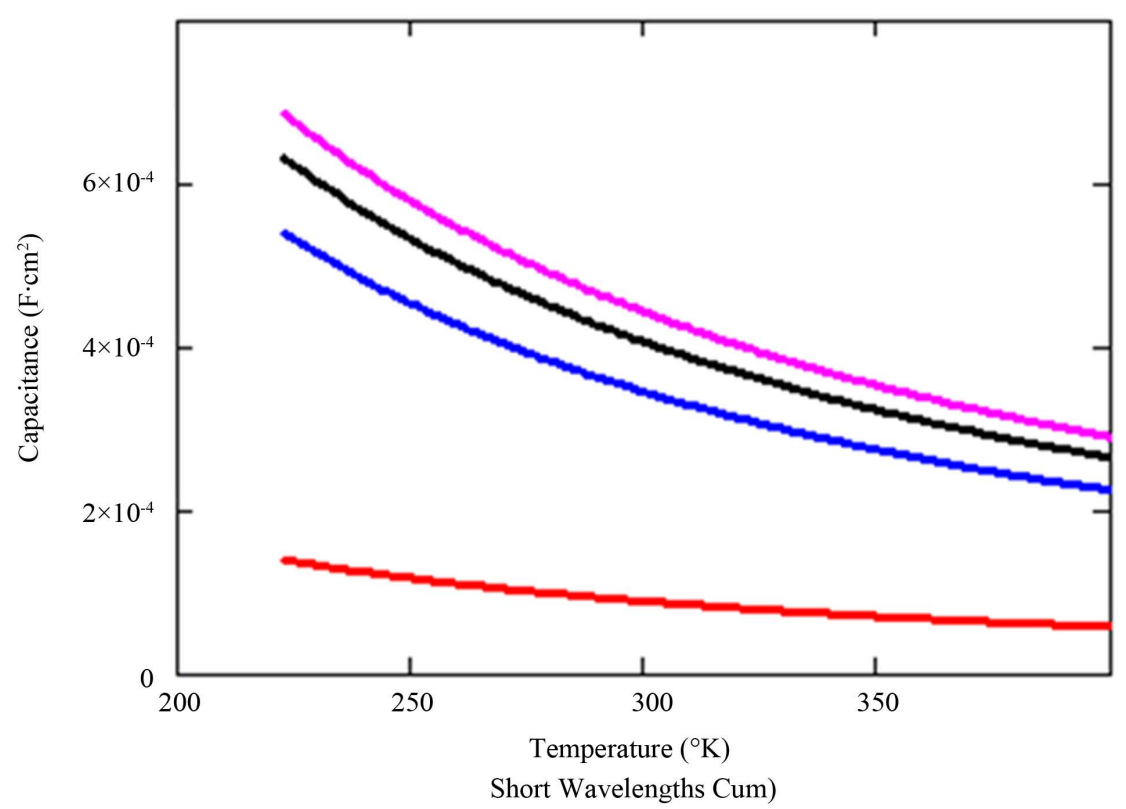

Figure 7. Capacitance of the solar cell open-circuit in function of temperature for small and different values of the wavelength $\left(S_{b}=2 \times 10^{2} \mathrm{~cm} / \mathrm{s}, S_{f}=0 \mathrm{~cm} / \mathrm{s}\right)$.

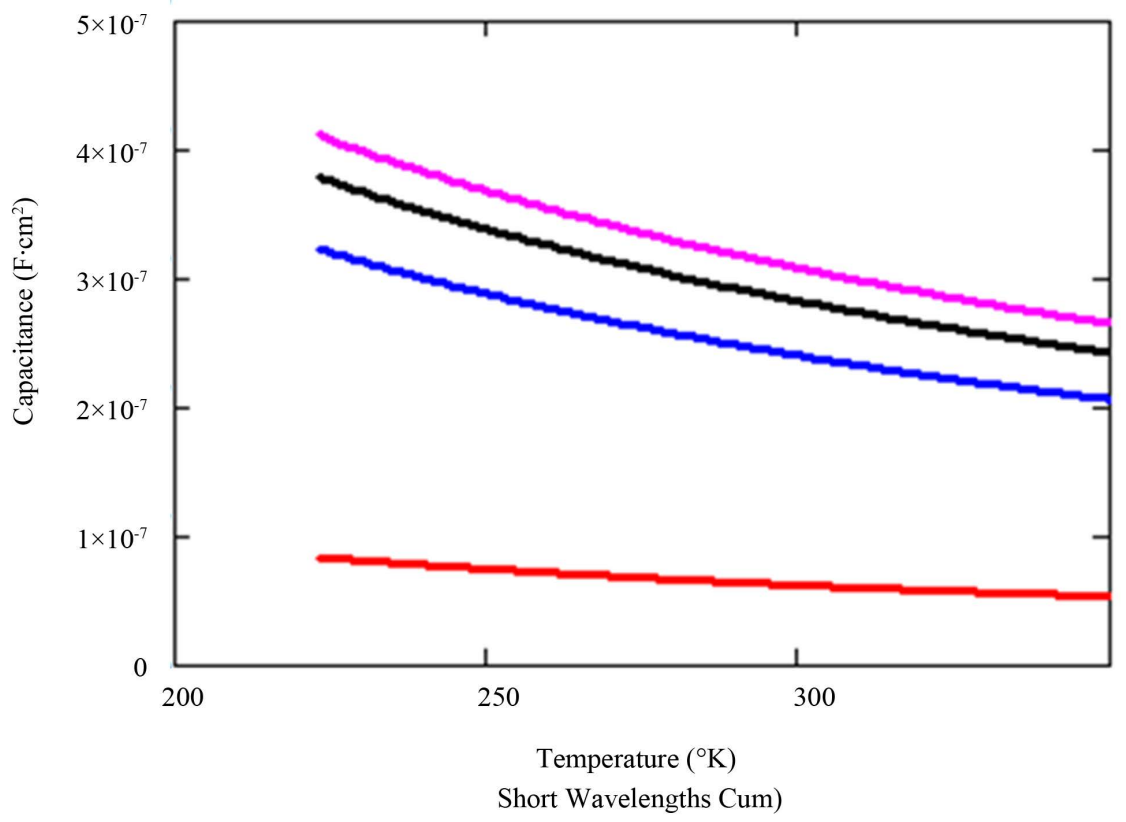

Figure 8. Capacitance of the solar cell by short-circuit function of temperature for different low and the wavelength values $\left(S_{b}=2 \times 10^{2} \mathrm{~cm} / \mathrm{s}, S_{f}=6 \times 10^{6} \mathrm{~cm} / \mathrm{s}\right)$.

multispectral illumination is presented. From different studies, we could establish that the temperature favors the presence of photo generated electrons in the base by inhibiting their diffusion and their conduction. The diffusion capacitance of the solar cell increases with the temperature. Finally, the dark capacitance of the solar cell was obtained for any temperature value on the capacitance 


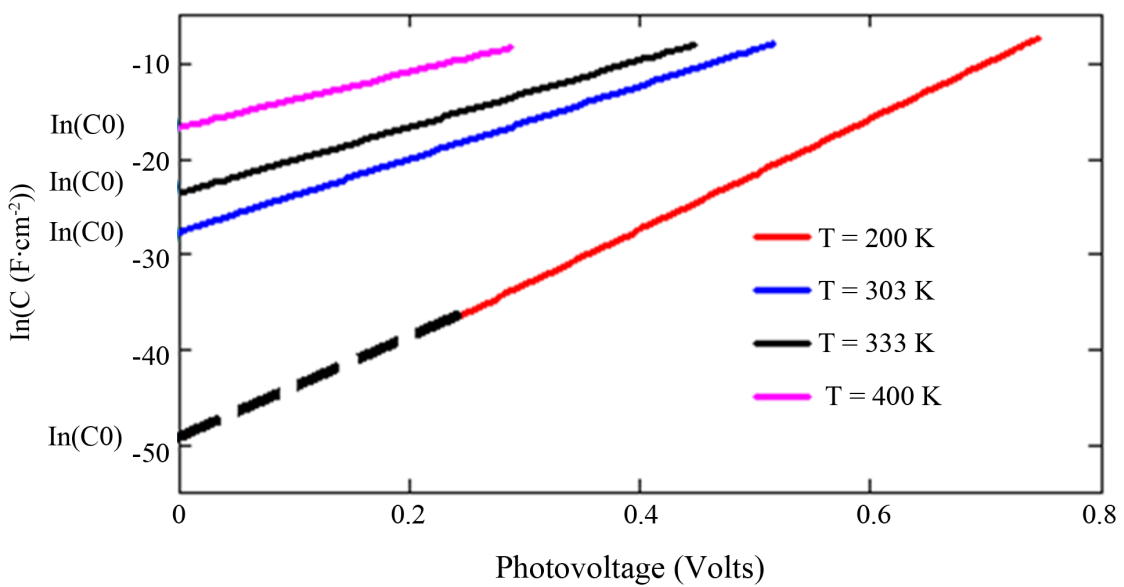

Figure 9. Logarithm of the capacitance versus photo voltage for various temperature values $\left(S_{b}=2 \times 10^{2} \mathrm{~cm} / \mathrm{s}, \lambda=0.48 \mu \mathrm{m}\right)$.

Table 1. $C_{0}$ (Capacitance darkness) values for the function of temperature.

\begin{tabular}{ccccc}
\hline$T$ & $200 \mathrm{~K}$ & $303 \mathrm{~K}$ & $333 \mathrm{~K}$ & $400 \mathrm{~K}$ \\
\hline$C_{0}$ & $8.54 \times 10^{-22} \mathrm{~F} \cdot \mathrm{cm}^{-2}$ & $1.01 \times 10^{-12} \mathrm{~F} \cdot \mathrm{cm}^{-2}$ & $5.25 \times 10^{-11} \mathrm{~F} \cdot \mathrm{cm}^{-2}$ & $5.21 \times 10^{-8} \mathrm{~F} \cdot \mathrm{cm}^{-2}$ \\
\hline
\end{tabular}

(open circuit in Short circuit, under dark). Based on the C-V characteristics, a graphical method has been proposed for the determination of dark capacitances $C_{0}$.

\section{References}

[1] Agroui, K. (1999) Etude du comportement thermique de modules photovoltaïques de technologie monoverre et biverre au silicium cristallin. Rev. Energ. Ren. Valorisation, 7-11.

[2] Meier, D.L., Hwang, J.-M. and Campbell, R.B. (1988) IEEE Transactions on Electron Devices, ED-35, No. 1, 70-78.

[3] Harold, J. (1975) Hovel semiconductors and semimetals, Volume 11 Solar Cells. Academic Press, New York, San Francisco, London.

[4] Hübner, A., Aberle, A.G. and Hezel, R. (2001) 20\% Efficient Bifacial Silicon Solar Cells. 14th European PVSEC, Munich, 1796-1798.

[5] Barro, F.I., Sane, M. and Zouma, B. (2015) On the Capacitance of Crystalline Silicon Solar Cells in Steady State. Turkish Journal of Physics, 39, 122-127. https://doi.org/10.3906/fiz-1408-3

[6] Mathieu, H. (1987) Physique des Semi-conducteurs et des Composants Electroniques. Masson, Paris, 601 p.

[7] Nadia, B.B. (2006) Propriétés physiques des semi-conducteurs (Si monocristallin et $\mathrm{Ge}$ ) et Simulation des cellules solaires à base de $\mathrm{Si}$ et $\mathrm{SiGe}$. Juillet.

[8] Sissoko, G., Museruka, C., Corréa, A., Gaye, I. and Ndiaye, A.L. (1996) Spectral Light Effect on Recombination Parameters of Silicon Solar Cell. Proceedings of World Renewable Energy Congress, Part 3, Denver, 15-21 June 1996, 1487-1490.

[9] Dieme, N. (2015) Influence of a Semiconductor Gap's Energy on the Electrical Parametersof a Parallel Vertical Junction Photocell. Energy and Power Engineering, 7, 
203-208. https://doi.org/10.4236/epe.2015.75020

[10] Stefano, D.E., Nicola, S., Federica, C., Carlo, V., Giuseppe, S. and Roberto, B. (2009) Ellipsometry Investigation of the Effects of Annealing Temperature on the Optical Properties of Indium Tin Oxide Thin Films Studied by Drude-Lorentz Model. Applied Surface Science, 255, 7203-7211. https://doi.org/10.1016/j.apsusc.2009.03.064

[11] Phyllips, J.E., Titus, T. and Hofmann, D. (1997) Determining the Voltage Dependence of the Light Generated Current in CuInSe2-Based Solar Cells Using I-V Measurements Made at Different Light Intensities. Proceedings of the 26th IEEE Photovoltaic Specialists Conference, Anaheim, CA, 29 September-3 October 1997.

[12] Anantha, K., Misra, N.K., Suresh, M.S. (2009) Solar Cell as a Capacitive Temperature Sensor. IEEE Log No. T-AES/47/2/940812.

[13] Untila, G.G., Kost, T.N., Chebotareva, A.B., Zaks, M.B., Sitnikov, A.M., Solodukha, O.I. and Shvarts, Z. (2013) Bifacial Low Concentrator Argentum Free Crystalline Silicon Solar Cells Based on ARC of TCO and Current Collecting Grid of Copper Wire. AIP Conference Proceedings, 1556, 106. https://doi.org/10.1063/1.4822210

[14] Alurralde, M., Tamasi, M.J.L., Bruno, C.J., Martinez Bogado, M.G., Pla, J., Fernandez Vazquez, J., Duran, J., Schuff, J., Burlon, A.A., Stoliar, P. and Kreiner, A.J. (2004) Experimental and Theoretical Radiation Damage Studies on Crystalline Silicon Solar Cells. Solar Energy Materials \& Solar Cells, 82, 531-542. https://doi.org/10.1016/j.solmat.2003.11.029

[15] Sahin, G. (2016) Effect of Wavelength on the Electrical Parameters of a Vertical Parallel Junction Silicon Solar Cell Illuminated by Its Rear Side in Frequency Domain. Results in Physics, 6, 107-111. https://doi.org/10.1016/j.rinp.2016.02.003

[16] Grigorieva, G., Kagan, M., Unishkov, V., Zviagina, K., Kreinin, L., Bordin, N., Broder, J., Eisenberg, Y. and Eisenberg, N. (2010) Efficiency of Bifacial Si Solar Cells at Low Irradiance. Effect of Design and Fabrication Technology Factors. Proceedings of the 25th European Photovoltaic Solar Energy Conferencel 5 th World Conference on Photovoltaic Energy Conversion, Valencia, 1805-1809.

[17] Ndiaye, E.H., Sahin, G., Dieng, M., Thiam, A., Diallo, H.L., Ndiaye, M. and Sissoko, G. (2015) Study of the Intrinsic Recombination Velocity at the Junction of Silicon Solar under Frequency Modulation and Irradiation. Journal of Applied Mathematics and Physics, 3, 1522-1535. https://doi.org/10.4236/jamp.2015.311177

[18] Sane, M., Sahin, G., Barro, F.I. and Maiga, A.S. (2014) Incidence Angle and Spectral Effects on Vertical Junction Silicon Solar Cell Capacitance. Turkish Journal of Physics, 38, 221-227.

[19] Sahin, G., Dieng, M., Moujtaba, M.A.O.E., Ngom, M.I., Thiam, A. and Sissoko, G. (2015) Capacitance of Vertical Parallel Junction Silicon Solar Cell under Monochromatic Modulated Illumination. Journal of Applied Mathematics and Physics, 3, 1536-1543. https://doi.org/10.4236/jamp.2015.311178 